\title{
Making the case for in-house training
}

By: Michael A. Crumpton

Michael A. Crumpton, (2011),"Making the case for in-house training", The Bottom Line: Managing Library Finances, Vol. 24 Iss: 3 pp. 167 - 172

Made available courtesy of Emerald Publishing:

http://www.emeraldinsight.com/journals.htm?issn=0888-045X

\begin{abstract}
*** Reprinted with permission. No further reproduction is authorized without written permission from the Emerald Publishing. This version of the document is not the version of record. Figures and/or pictures may be missing from this format of the document.***
\end{abstract}

\begin{abstract}
:
Purpose - The purpose of this paper is to provide the structure needed to create an in-house training program for libraries as a means for improving staff competencies during periods of economic problems.

Design/methodology/approach - The paper pulls information from the business environment and gives a human resources perspective on training programs used in companies that also have limited financial means.

Findings - The information and structure provided for development of a training program has had proven results.

Practical implications - This information will require action on the part of libraries interested in gaining this advantage.

Originality/value - These proven methods and steps can increase a library's case when seeking to justify allocation of resources and will add value to the organization as it serves its primary clientele.

Article:

In these tough financial times, many limitations can be imposed on libraries that foster a culture of staff and/or professional development. Hiring activities shift to more transitional activities; including assessing training needs and gaps in the skills sets of incumbent staff. In good economic times the human resource function expands on staffing, employee involvement programs and training. In poor times these activities are usually the first to go in the cutbacks. However; the need is never greater to invest in training programs and activities that provide additional organizational agility and flexibility as hiring new staff is disrupted. Libraries must put on their human resources hat in order to continue to provide these developmental needs, in particularly during tough economic times.

In a Journal of Management (27) article by three human resource colleagues at Cornell University, "Human resources and the resource based view of the firm", the strategic use of human resource management is discussed as it relates to the use of human capital as a resource. The development of human capital, by training internally, is vulnerable to not only hard economic times, but also to a variety of arguments for outsourcing or detaching the training function so that it becomes an external activity. Libraries are full of individual expertise that
\end{abstract}


should be nurtured and shared in order to gain the organizational benefit for all staff. This could play an important role in how the library is viewed within the larger institution, and how staff could maintain a competitive advantage within the field.

The following human resources perspective is meant to give suggestions and make the case for in-house training programs, which libraries can develop to improve their positioning with human capital. Libraries have many potential resources for developing training content including inhouse knowledge, collaborative partnerships with other libraries and consortiums and vendors who are willing to contribute to content and skill development needs. Proper attention must be given to the assessment and development of a program that ensures effective use of time and money and will lead to enhancement of organizational value.

\section{Resource-based view of human resources}

Wright and McMahan in 1992 presented the resource-based view as one perspective in determining that an organization's human resources could provide a potential source of competitive advantage. This resource-based view combines the analysis of a company's internal activities with the external analysis of the industry and the competitive environment. This is a theoretical rationale for human resources having implications for forming strategy as well as implementation of objectives. For libraries this puts the focus on staff and their usefulness to the end user over resources and materials that may have been purchased or needs to be accessed.

But human resource practices do not form the basis for a competitive advantage or justification of receiving consideration for shared resources. It is the human capital pool (staff) that has the potential to create the advantage with both a high level of skill and willingness to perform. The distinction is the skill set, creating a talented and committed workforce and the development of employees that are capable of learning. The successful results of this will be a competitive advantage or increased value of the organization.

Regarding strategy, in a Harvard Business Review article, "What is strategy?” (1996), Michael E. Porter discusses the difference between strategy and operational effectiveness. Operational effectiveness, while necessary for the competitive advantage or justification of resources, really means performing similar activities better than could be done by others. Strategy is about being different and developing unique activities that are different than the competition. This should be reflected in the training programs that are delivered to employees and can affect the resulting behavior, such as developing programs that embrace the unique aspects of librarianship.

\section{What's the training or developmental need?}

A good starting place for determining training needs is a self-assessment. As an example, the federal government, which employees a diverse group of individuals with a broad range of skills and knowledge requirements, has put together a Human Capital Self-Assessment Checklist for their Agency Leaders (www.gao.gov/special.pubs/cg00014 g.pdf). It recognizes that human capital or people, are assets whose value can be enhanced through investment, or training. It also recognizes that human capital policies must be designed, implemented and assessed by a shared vision or strategy of the organization. 
Libraries who are faced with downsizing or reduced resources and cannot pursue new initiatives, must assess the current human capital skills sets in order to address repurposing opportunities that will be necessary to maintain currency and value to the larger, ever changing, institution.

The example self-assessment checklist relates to the competitive strategy that an organization can formulate for its workforce. It is organized as follows:

- Strategic planning: establishes the mission, vision, core values, goals and objectives and strategies.

- Organizational alignment: integrates human capital into the organization's core business practices.

- Leadership: fosters a committed leadership team that supports the strategic planning process.

- Talent: recruit, hire and train employees to develop skills and behaviors needed for the competitive advantage.

- Performance culture: motivate workforce through empowerment.

This self-assessment checklist then provides direction regarding formal training programs or a human capital development process for federal government employees. Libraries have similar resources available that can contribute to an overall training program.

\section{Developing the training program}

The decision now is regarding the formulation of a Training Program that not only fits the library's strategic plans, but also creates the infrastructure that supports the development of human capital to gain a competitive advantage within the market and for service to the institution. A training needs assessment would be appropriate and a good starting point to determine the direction needed.

According to the Society for Human Resource Management (Learning System, 2008), conducting a needs assessment is valid for the following reasons:

1. To determine "IF" training is needed - Training needs can be a result of poor performance, competition, a decline in business or morale issues. This can avoid applying training to a non-training problem. For the library environment, this can also mean that a decline in resource allocation or hiring restrictions imposed could create a training need.

2. To determine the cause of poor performance - Poor performance can have many causes in business, including professionals feeling that they have fallen behind the learning curve.

3. To determine content and scope of training - The type of training is important to achieve expected results. You want to do what is best for the situation logistically, workshop, self-study, OTJ, etc. in order to achieve maximum learning. Also you want to determine when, who and to what degree training is needed.

4. To determine desired training outcomes - This identifies what knowledge, skills, and behaviors are targeted for competitive advantage. 
5. To provide a basis or measurement - A needs assessment will establish a baseline in which to measure results or changes.

6. To gain management support - This creates the leadership commitment needed to be successful.

The methods for conducting a needs assessment are varied and could be discussed in great lengths.

\section{Job analysis and core competencies}

A needs assessment could also include a job analysis and a review of the core competencies that are essential in fulfilling the job successfully. From a job analysis, a job description is created and used for recruiting and the posting of openings. Job specifications are the knowledge and skills that are perceived as being required to do the job successfully. This is the basis for the whole recruiting and hiring process in the human resource environment. Or in the case of nonhiring, this could be the basis for re-purposing positions to maintain focus on organizational priorities.

Core competencies are the basic skill level and purpose of any given professional position. The goal of successful recruitment and interviewing is to match a candidate's experience and skill set, with the core competencies of the job as close as possible. The goal of the successful candidate is to develop the skills, through education, experience or additional training to match the position that they seek. Employers must identify the organizational need or competencies within position requirements and seek job candidates who are trained to match those competencies or plan training programs that create skill equity.

In "Designing and implementing an HR Scorecard”, by Walker and MacDonald, 2001, a discussion of training investment vs recruiting expenses makes a strong case for internal training programs to create the core competencies needed by organizations. This is helpful for both succession planning, backing up specialty or unique skills needed and re-purposing people as needed within the organization in order to perform prioritized tasks.

\section{To in-house or out-sourced?}

Training programs are expensive and time consuming. Whether a training program is developed in-house or outsourced the cost can be high. Typically only larger companies or organizations can afford to totally provide the needed training in-house. Outsourced training firms have grown substantially over the years, seeking medium and small companies that have smaller training programs as their target market. Some larger companies will supplement their in-house programs with external programs for various reasons. Recruitment and hiring of experience and skill sets already trained avoid the cost of training but add cost in different areas, including recruitment, as mentioned earlier. Katherine Morrall, in her article, "Bring training in-house”, Bank Marketing (1996), makes the point to consider several options, but recommends keeping your core training activity in-house. 
The decision regarding whether or not to outsource training activity also depends on the strengths and weaknesses of the organization. An organization that does not have the resources in-house to provide the training and development needed by the workforce has other problems as well. Within the field of librarianship, skills and talents are plentiful and should be harvested to provide value and support for an in-house program. Other arguments for in-house development include:

- In-house training should relate to in-house culture. Programs developed internally can be tailored to match company strategy, goals and objectives.

- Leadership buy-in is stronger when a training program is proprietary as it also provides the opportunity to influence the material.

- In-house training should be viewed as an investment, as opposed to a cost. This investment in human capital can be measured in the evaluation process.

- Outsourcing of training programs creates the need to provide the outsourcing company with company information that go beyond typical public assessable material. This is not good for the competitive advantage of being different or unique because despite confidentiality agreements information has "left the building".

A good argument for the use of outsourcing training activity is when the need is a universal topic, an industry expert or a product compliance type of need. In these cases the options that should be explored should be more logistical in nature. In-house training can supplement external sources through satellite hook-ups, teleconferencing or distance learning programs and keep the core foundation of behavior modification in-house.

\section{Evaluating the program}

Regardless of the type of training program developed and implemented, training becomes an expense, viewed as either a cost or an investment. How do you justify these costs or ensure that the program is effective enough to create a return on that investment?

The current and most common evaluation method of training programs is monitoring. But the true benefits of training are not easily measured in quantitative terms. Especially programs in which behavior modification is expected to gain a competitive advantage. This requires a longerterm view of measurement and moves from monitoring to evaluation.

In an article by Christopher Rowe, "How useful was it: the problem of evaluating in-house training programs”, the following five-step model of evaluation was developed at British Aerospace at Brough to determine the long-term effects of their training programs and this could represent the basic elements for any in-house training evaluation.

- Level One: Instance monitoring of new skills through questionnaires.

- Level Two: Project work that provides trainees the opportunity to assess their own learning development.

- Level Three: Interviews in the work environment to encourage discussion of direct application of the training program's content. 
- Level Four: An evaluation of awareness and behavior changes, of the trainees, by senior management.

- Level Five: An evaluation of the company's business performance through a variety of methods utilizing the training material.

While evaluation of training is never an exact science, long-term evaluation by all members of the organization helps to reinforce the material and sustain behavioral changes indefinitely.

\section{Conclusion}

In an organization that is truly committed to the utilization of human capital, in order to gain a competitive advantage in the marketplace or in the case of most libraries justifying their need for resources, in-house training programs are the most effective to the long term success of the organization's strategic goals. Training should be seen as an investment in the organization's strategic plans and internal training should be seen as an investment in the current workforce.

To compete strategically, you must first determine the training need through self-assessment, develop a training program that will support the job analysis and core competencies needed then determine whether or not you have the resources internally to train "competitively".

Outsourcing training programs can be impersonal and lack the culture and teamwork that reinforces training values. Collis and Montgomery, in the Harvard Business Review (1995), site many successful companies that utilize in-house training programs, in their article "Competing on resources: strategy in the 1990s". These companies all pride themselves on the internal teamwork and personal standards that they establish within their organization. Libraries have this same opportunity to foster a learning culture internally and preserve their value to their respective clientele. 